\title{
Proinflammatory and Prothrombotic EfFects on Human VAscular Endothelial Cells of ImMune-CELl-DERIVEd LIGHT
}

\author{
S. Celik ${ }^{1 *}$, V. Shankar ${ }^{1 *}$, A. Richter ${ }^{1}$, H.-J. Hippe ${ }^{1}$, M. Akhavanpoor ${ }^{1}$, F. Bea ${ }^{1}$, C. Erbel ${ }^{1}$, S. Urban ${ }^{2}$, \\ N. Blank ${ }^{3}$, N. Wambsganss ${ }^{1}$, H. A. Katus ${ }^{1}$, T. J. Dengler ${ }^{1}$ \\ ${ }^{1}$ Department of Cardiology, University of Heidelberg, INF 410, Heidelberg, \\ ${ }^{2}$ Department of Molecular Virology, Otto Meyerhof Zentrum, University of Heidelberg, INF350, Heidelberg, \\ ${ }^{3}$ Department of Rheumatology, University of Heidelberg, INF 410, Heidelberg, Germany
}

\begin{abstract}
Objective: LIGHT (TNFSF 14) belongs to the tumor necrosis factor superfamily and is expressed by activated $\mathrm{T}$ cells as well as various types of antigen presenting cells. LIGHT binds to its cellular receptors TR2 and LTBR and has a co-stimulatory role in T cell activation. Here, we compared the relative expression of LIGHT in different immune cells and the biological activity of immune cell-derived LIGHT on endothelial cells.

Methods and Results: Surface expression of LIGHT and mRNA production by PBMC and isolated T cells $\left(\mathrm{CD}^{+}\right.$or $\left.\mathrm{CD}^{+}\right)$significantly increased after stimulation with PMA (Phorbolester-12- Myristat-13-Acetat) + ionomycin. No LIGHT expression on PMA stimulated monocytes or monocytic-like THP-1 cells could be detected; differentiation of monocytes and THP-1 cells into macrophages, however, resulted in up-regulation of LIGHT. Supernatants of stimulated T cells contained higher concentrations of soluble LIGHT than macrophage supernatants normalized to cell numbers; release of soluble LIGHT was found to be dependent on metalloproteinase activity. Size determination of released soluble LIGHT by size exclusion chromatography revealed a molecular mass of $\sim 60$ $\mathrm{kDa}$, suggesting a trimeric form. Released soluble LIGHT induced expression of proinflammatory antigens ICAM-1, tissue factor and IL- 8 in human endothelial cells and caused apoptosis of IFN- $\gamma$ pretreated endothelial cells. Soluble LIGHT was detected at low levels in sera of healthy controls and was significantly enhanced in sera of patients with chronic hepatitis $C$ and rheumatoid arthritis $(24.93 \pm 9.41$ vs. $129.53 \pm 49.14$ and $172.13 \pm 77.64 ; \mathrm{p}<0.0005)$.

Conclusion: These findings suggest that among immune cells activated $\mathrm{T}$ lymphocytes are the main source of soluble LIGHT with released amounts of soluble LIGHT markedly higher compared to platelets. Immune cell-derived membrane-bound and soluble trimeric LIGHT is biologically active, inducing proinflammatory changes in endothelial cells. Enhanced plasma levels of soluble LIGHT in patients with chronic infections suggest a role of LIGHT in systemic inflammatory activation.

Key words: LIGHT, endothelial cells, inflammation
\end{abstract}

\footnotetext{
* These authors contributed equally to this work.
}

\section{INTRODUCTION}

The tumor necrosis factor related cytokines provide essential communication pathways that help orchestrate inflammatory and immune responses. They play an integral role in regulation of innate and adaptive immunity $[1,2]$. LIGHT belongs to the tumor necrosis superfamily and acts as a co-stimulatory molecule for $\mathrm{T}$ cells, including the enhancement of $\mathrm{T}$ cell proliferation and secretion of IFN- $\gamma$. LIGHT exists in a membranebound and soluble form. It is a ligand for TR2, LTßR and TR6, all of which are TNF receptor family members. Studies in animal models suggest that LIGHT signaling pathways may be crucial for the development of various autoimmune disorders, at least in part because of their effects on $\mathrm{T}$ cells and T-cell homing into inflamed tissues $[3,4]$. In an experimental mouse model it was shown that soluble LIGHT is involved in the pathogenesis of hepatitis via LIGHT-LTßR interaction [5]. Several studies suggest that LIGHT is involved in atherogenesis via induction of proatherogenetic cytokines and decreasing plaque stability by inducing metalloproteinase activity in macrophages [6].

Recently, Otterdal et al. [7] reported that LIGHT was associated with platelets und released upon activation. Thrombus material obtained at the site of plaque rupture in patients with STEMI (ST segment elevation myocardial infarction) contained platelet-derived LIGHT, suggesting platelets as the origin of LIGHT. In line with these findings we previously showed that the adhesion of platelets to endothelial cells is mediated by platelet-LIGHT [8]. Furthermore, patients with STEMI showed enhanced plasma levels of soluble LIGHT compared to healthy controls $[5,10]$. Recently, it was shown that concentrations of platelet-derived cytokines are markedly influenced by preclinical conditions and may be released only ex vivo [9]; raising the question if soluble LIGHT in patient sera really originates from platelets or possibly from other cell types, e. g. lymphocytes or macrophages. Similarly, the origin of circulating soluble LIGHT in other human autoimmune or inflammatory disease states (rheumatoid arthritis, infection) has not yet been studied - leaving the relative contribution of different cell types to circulating soluble LIGHT unresolved.

In the present study we analyzed different immune cells for expression and the release of membranebound and soluble LIGHT to quantify the different 
sources of LIGHT. Our findings show that T lymphocytes show high expression levels of membranebound and release large amounts of soluble LIGHT while monocytes and THP-1 cells only begin to express LIGHT upon differentiation into macrophages. Release of soluble LIGHT is shown to be matrix metalloproteinase-dependent, soluble LIGHT appears to be shed as a trimeric form which is biologically active.

Finally, enhanced serum levels of soluble LIGHT were detected in patients with chronic inflammatory disorders.

\section{Methods}

\section{Cell Culture}

Human umbilical vein endothelial cells were isolated from umbilical cords by enzymatic digestion as previously described [10] and serially cultured in medium.

PBMC were obtained from healthy adult volunteers by density gradient centrifugation of heparinized venous blood. Mononuclear cells were collected from the interphase after Ficoll separation (Amersham Pharmacia Biotech, Freiburg, Germany). For the isolation of the single subpopulations of PBMCs magnetic Micro-Beads (Miltenyi Biotec, Bergisch Gladbach, Germany) were used according to the manufacturer's instructions. A total of $2.5 \times 10^{6} \mathrm{~T}$ cells per $\mathrm{ml}$ were stimulated with $100 \mathrm{ng} / \mathrm{ml}$ PMA (Sigma, Germany) and $1 \mu \mathrm{g} / \mathrm{ml}$ ionomycin (Sigma) for different time of points. Human monocytic cell line THP-1 was cultured in RPMI medium.

THP-1 cells were differentiated by overnight incubation with PMA (100 ng/ml).

PMA-differentiated THP-1 macrophages were stimulated in 12 -well plates $\left(2.5 \times 10^{6}\right.$ cells $/ \mathrm{ml}$, Nunclon $)$ with TNF- $\alpha$ (10 ng/ml; Sigma, Germany) for 2, 4 and 16 hours.

Monocytes were isolated from PBMC using magnetic beads and cultured in RPMI medium in the presence of cytokine MCSF at a concentration $100 \mathrm{nM}$ for 6 days to generate macrophages. Differentiation of monocytes into macrophages was confirmed by the surface expression of CD80 and CD86. Stimulation of macrophages was performed in 12 -well plates $\left(5 \times 10^{6}\right.$ cells $/ \mathrm{ml})$ with TNF- $\alpha(10 \mathrm{ng} / \mathrm{ml})$ for 2,4 and 16 hours.

For the generation of the supernatants $2.5 \times 10^{6}$ cells in $1 \mathrm{ml}$ medium of each cell were activated respectively for 24 and 48 hours.

LIGHT CDNA, CONSTRUCTION OF LIGHTcontaining Vector and Cell Transfection

Total RNA isolated from T cells was used to generate cDNA by RT-PCR (MBI-Fermentas). Total RNA was prepared from T cells using QiaAmp RNA blood mini kit. LIGHT cDNA was amplified by PCR using pfu DNA polymerase (Stratagene). The size of LIGHT cDNA was 731 bp. LIGHT cDNA was then cloned in to plasmid pcDNA 3.1D/V5-His-TOPO (Invitrogen, Germany) to generate p'TOPOLIGHT. The integrity of pTOPOLIGHT was confirmed by restriction digestion analysis and sequencing.
Transfection of 293 cells

293 cells were transfected with plasmid p'TopoLIGHT using Superfectin reagent (Qiagen) as recommended by the manufacturer.

\section{Gel Exclusion Chromatography}

Isolation of soluble LIGHT from culture supernatant of transiently LIGHT-expressing 293 cells or PMA + ionomycin stimulated PBMC and determination of apparent molecular weights of proteins and protein complexes were achieved by size exclusion chromatography on a calibrated Superdex 200 column (1.6 _ 60 $\mathrm{cm}$; Pharmacia), connected to a FPLC system (Pharmacia). Sample volumes were $0.5 \mathrm{ml}$ for analytical and up to $2 \mathrm{ml}$ for preparative purposes. Eluted proteins were collected in fractions of $2.2 \mathrm{ml}$, concentrations determined by ELISA subjected to SDS-PAGE, and analyzed by silver staining or immunoblotting. (3 fractions of isolated soluble LIGHT from PBMC supernatant were pooled and used for endothelial cell stimulation assays).

\section{Filtration of LIGHT CONTAINING SUPERnATANTS}

LIGHT containing medium $(500 \mu \mathrm{l})$ was collected from stimulated PBMC, pipetted into the sample reservoir of Microcon $30 \mathrm{kDa}, 50 \mathrm{kDa}$ and $100 \mathrm{kDa}$ cutoff centrifugal filter device (Millipore Corp., Bedford, Massachusetts, USA) and centrifuged according to the manufacturer's instructions. For the calculation of percent filtrate and retentate recovery a corresponding formula provided by the manufacturer was used.

\section{Western BLot ANALYSis}

Western blotting was performed according to standard procedures. For western blotting of the supernatants of activated PBMCs, Microcon centrifugal filters YM50 were used to concentrate soluble LIGHT and then suspended in SDS sample buffer for SDS-PAGE $(12-15 \%)$. The separated proteins were transferred electrophoretically to nitrocellulose membranes, and immunodetection was carried out using specific antibodies against LIGHT. Peroxidase-conjugated donkey anti-rabbit were used, and detection was carried out with an enhanced chemiluminescence (ECL) reagent (Pierce). Chemiluninescence was quantified using a FluorS-MultiImager (BioRad, Munich, Germany).

\section{FLOW CyTOMETRY}

Expression of LIGHT on THP-1 cells, CD4 ${ }^{+}, \mathrm{CD}^{+}$ and $\mathrm{CD} 14^{+}$was measured by indirect immunofluorescence flow cytometric analysis.

Cells were processed following standard procedures as described before [11]. A total of $5 \times 10^{5}$ cells were stimulated with PMA (Phorbolester-12- Myristat-13Acetat; $100 \mathrm{ng} / \mathrm{ml})+$ ionomycin $(1 \mu \mathrm{g} / \mathrm{ml})$ or TNF- $\alpha$ and stained with anti- LIGHT or control antibodies for 60 minutes at $4{ }^{\circ} \mathrm{C}$ in the dark. All analyses were performed on flow cytometer (Becton Dickinson, Heidelberg, Germany) using CellQuest software FACScan (BD Biosciences, Heidelberg, Germany). 
ReAl Time-PCR ANALysis of mRNA Expression

The mRNA expression of ICAM-1, IL-8, B-Actin and LIGHT was evaluated by Real Time PCR with LightCycler (Roche, Germany) according to the manufacturer`s instructions.

A long (NM_003807) and short (NM_172014) form of LIGHT RNA has been reported earlier. To distinguish both types of RNA, PCR primers which spans the region missing in the shorter form was designed. By using RT-PCR, the presence of longer or a shorter RNA form was detected by amplicon having product sizes of 194 bps and 84 bps respectively.

\section{Determination of Tissue Factor Activity in HUVEC By ONE-STAge ClotTing Assay}

One-stage clotting assays were performed as previously described [12]. Human endothelial cells (106/well) were incubated with isolated soluble LIGHT for 6 hours. TF activity was calculated by comparing the measured clotting time with a standard curve made with known amounts of TF. The measured amount of TF was expressed as picograms of $\mathrm{TF} / 10^{6}$ cells \pm S.D.

\section{ELISA ASSAYS}

Plasma levels of LIGHT in patients with hepatitis C and rheumatoid arthritis and LIGHT expression in the supernatants of stimulated cells was performed by ELISA according to the manufacturer's instructions ((R\&D Systems, Wiesbaden, Germany)

\section{Apoptosis Assay}

Endothelial cells $\left(10 \times 10^{5}\right.$ cells / well) were cultured with endothelial cell medium and preincubated with IFN- $\gamma(250 \mathrm{U} / \mathrm{ml})$ for 24 hours and then stimulated with cycloheximide $2.5 \mu \mathrm{g} / \mathrm{ml}$ (ICN Biomedicals) in combination with TNF- $\alpha(10 \mathrm{ng} / \mathrm{ml})$ or recombinant LIGHT (100 ng/ml).

After stimulation for 24 hours the cells were harvested and washed in PBS following fixation in cold $70 \%$ ethanol. After fixation for at least $30 \mathrm{~min}$ at $4{ }^{\circ} \mathrm{C}$, cells were washed twice with PBS and stained with 50 $\mu \mathrm{g} / \mathrm{ml} \mathrm{RNase}$ and $50 \mu \mathrm{g} / \mathrm{ml}$ propidium iodide (Sigma) and analyzed by FACS.

\section{PATIENTS}

22 patients, 15 females, age range 25 - 69 years, with rheumatoid arthritis defined by American College of Rheumatology criteria [13], were identified in rheumatology clinic with approval from the local research ethics committee.

10 patients (6 female; age range $18-50$ years) with chronic hepatitis $\mathrm{C}$ infection (defined by positive serum antibodies to HCV by means of a second or third generation HCV enzyme linked immunosorbent assay and detectable serum HCV RNA) were recruited to the study. Plasma samples from all individuals were collected and stored at $-80^{\circ} \mathrm{C}$ until analysis.

16 healthy volunteers (10 female; age range $20-48$ years) with no previous diagnosis of RA or other chronic inflammatory diseases served as normal controls.

Participating subjects gave written informed consent. The investigation conforms to the principles outlined in the Declaration of Helsinki.

\section{Data Presentation and Statistics}

Comparisons between group means were performed using Mann-Whitney U-test, Student t-test or ANOVA analysis as appropriate. Data are presented as mean + SD. $\mathrm{P}<0.05$ was considered as statistically significant.

\section{RESULTS}

\section{Expression of LIGHT ON DiffERENT ACTIVATED IMMUNe CELLS}

Stimulation of purified $\mathrm{CD}^{+}$and $\mathrm{CD}^{+}{ }^{+} \mathrm{T}$ cells with PMA $(100 \mathrm{ng} / \mathrm{ml})+$ ionomycin $(1 \mu \mathrm{g} / \mathrm{ml})$ induced a marked increase in surface expression of LIGHT. No LIGHT expression could be detected on monocytes and undifferentiated THP-1 cells after stimulation with TNF- $\alpha(10 \mathrm{ng} / \mathrm{ml})$. All cells were stimulated for 24 hours and analyzed by flow cytometry (Fig.1).

\section{MRNA EXPRESSION OF LIGHT IN ACTIVATED IMMUNE CELLS}

mRNA LIGHT expression in resting and stimulated T cells (PMA $100 \mathrm{ng} / \mathrm{ml}+$ ionomycin $1 \mu \mathrm{g} / \mathrm{ml}$ ), monocytes, macrophages and differentiated THP-1 cells ('TNF- $\alpha 10 \mathrm{ng} / \mathrm{ml}$ ) following specific time patterns (2, 4 and 16 hours) was evaluated by RT-PCR. LIGHT levels increased in response to stimulation with a maximum at $2-4$ hours after activation in $\mathrm{T}$ cells, macrophages and differentiated THP-1 cells (Fig. 2A $2 \mathrm{C})$. No mRNA expression for LIGHT was seen in undifferentiated monocytes. In all mRNA / PCR experiments only a single band of LIGHT cDNA was detected, even using specifically designed primers to detect a potential differentially spliced mRNA form (see methods).

\section{Release of Soluble LiGHT by Activated Immune CELls}

Secretion of soluble LIGHT into the supernatants of PBMC or stimulated $\mathrm{CD}^{+}$and $\mathrm{CD}^{+}$(PMA 100 $\mathrm{ng} / \mathrm{ml}+$ ionomycin $1 \mu \mathrm{g} / \mathrm{ml}$ ) monocytes, macrophages, THP-1 cells and differentiated THP-1 (TNF- $\alpha$ $10 \mathrm{ng} / \mathrm{ml}$ ) cells was analyzed by ELISA. Significant concentrations of soluble LIGHT could be detected in the supernatants of $\mathrm{PBMC}$ or $\mathrm{CD}^{+}$and $\mathrm{CD}^{+}$cells and differentiated THP-1 cells, which increased markedly upon cell activation, but not in monocytes and undifferentiated THP-1 cells. Differentiated THP1 and $T$ cell supernatants contained similar amounts of soluble LIGHT. Supernatant concentrations of LIGHT were higher in the $\mathrm{CD}^{+}$subset than in $\mathrm{CD}^{+}$ cells (Fig. 2D). A low concentration of soluble LIGHT was detected in the supernatants of stimulated monocyte-derived macrophages. 

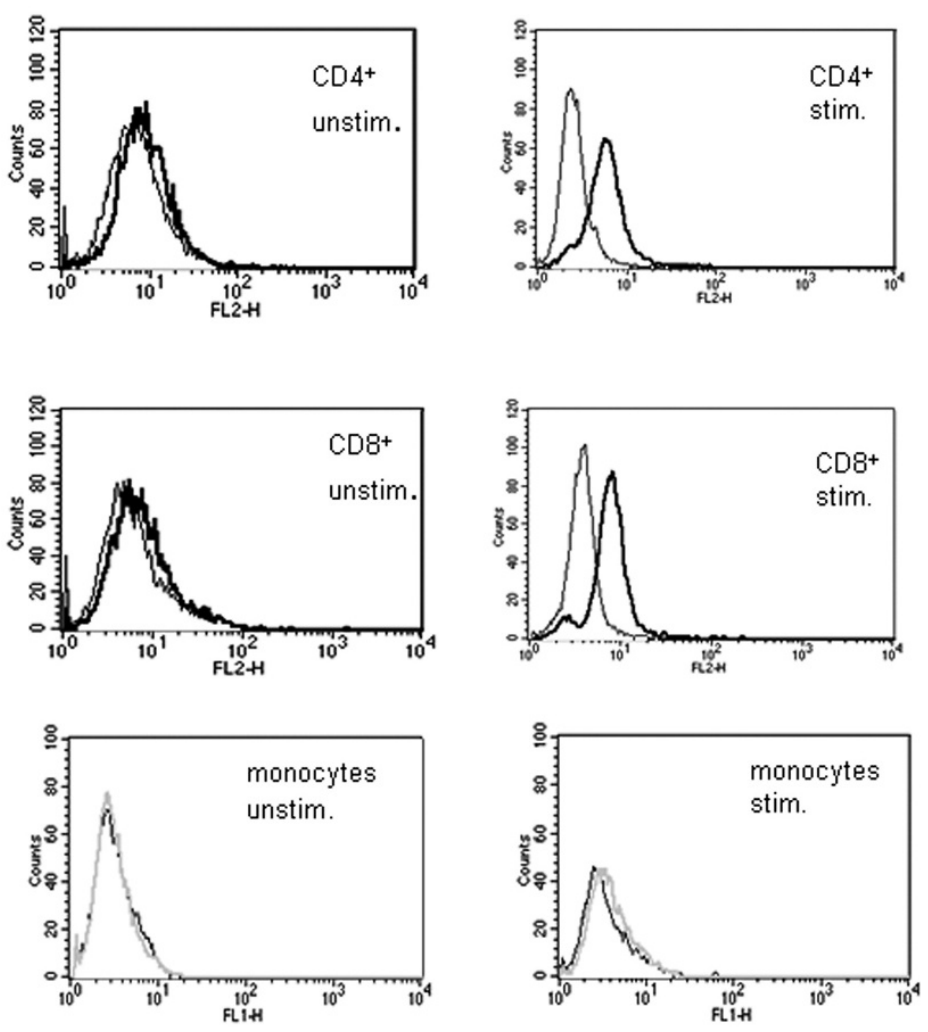

Fig. 1. Surface expression of LIGHT on $\mathrm{CD}^{+}$and $\mathrm{CD}^{+}$. Expression of LIGHT on the surface of $\mathrm{CD}^{+}$, $\mathrm{CD}^{+}, \mathrm{CD}^{+} 4^{+}$and THP-1 cells was measured by FACS.
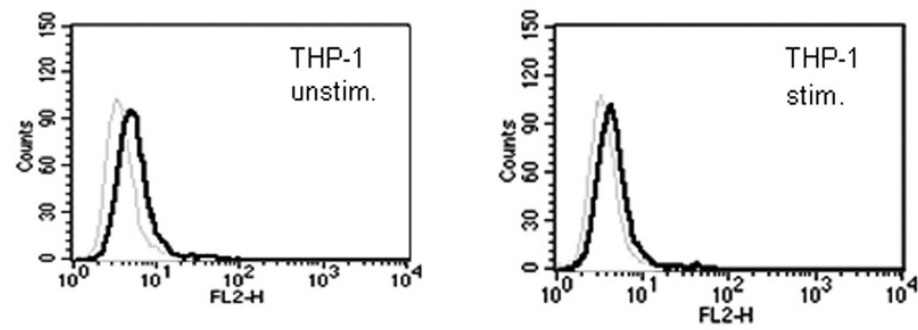
Cells were stimulated with PMA and ionomycin for 24 hours and stained with anti-LIGHT monoclonal antibody. LIGHT was not detectable on unstimulated cells, but activation of the cells resulted in appearance of LIGHT on the cell surface of $\mathrm{CD} 4^{+}$and $\mathrm{CD} 8^{+} \mathrm{T}$ cells, but not on monocytes and THP-1 cells. Thin curves correspond to the negative control and thick black curves correspond to specific staining for LIGHT. These data correspond to one representative experiment of three performed (Fig. 1).

In all cell types the specificity of ELISA results was supported by identical findings after ultrafiltration (30000 rpm, $12 \mathrm{~h}$ ).

\section{SOluble LIGHT is GenERATED THROUGH Proteolytic Cleavage of mLight by Matrix METALLOPROTEINASE INHIBITORS}

The involvement of metalloproteinases in the regulation of soluble LIGHT was investigated by testing the effect of a broad-spectrum synthetic metalloproteinase inhibitor (GM6001, a hydroxamate inhibitor of MMPs). GM6001 $(30 \mu \mathrm{M})$ inhibited significantly the release of soluble LIGHT into the supernatant of peripheral blood mononuclear cells and isolated $\mathrm{CD}^{+}{ }^{+} \mathrm{T}$ cell subset (Fig. 3A and B) when added 30 minutes prior and during the stimulation with PMA $100 \mathrm{ng} / \mathrm{ml}+$ ionomycin $1 \mu \mathrm{g} / \mathrm{ml}$.

\section{Monomeric Size of Soluble LiGHT}

Western blot analysis (reducing conditions) of lymphocyte derived soluble LIGHT revealed a molecular mass of approximately $\sim 23-25 \mathrm{kDa}$, similar to the molecular mass of recombinant soluble LIGHT (25 kDa), which represents only the extracellular part (Fig. 4).

\section{Size Determination of Soluble LiGHT}

For initial estimation of the molecular mass of soluble LIGHT filters with a molecular weight cut- off values of $>100 \mathrm{kDa}, 50 \mathrm{kDa}$ and $30 \mathrm{kDa}$ were used. Retentate fraction of soluble LIGHT in microcon filters with $30 \mathrm{kDa}$ and $50 \mathrm{kDa}$ molecular weight cut off was about $90 \%$. Spinning of soluble LIGHT through a filter with a $100 \mathrm{kDa}$ MWCO resulted in a $\sim 30 \%$ retentate fraction, indicating a molecular mass of soluble LIGHT between 50 - $100 \mathrm{kDa}$.

Size determination of lymphocyte-derived soluble LIGHT by size exclusion chromatography on a calibrated Superdex 200 gel filtration column resulted in a molecular mass of approximately $60 \mathrm{kDa}$, indicating a trimeric form of soluble LIGHT. The apparent molecular mass of soluble LIGHT was calculated from standard curves as a mean value of three independent measurements (data not shown).

\section{INFLAMMATORY EFFECTS OF LyMPHOCYTE DERIVED LIGHT ON HUVEC}

To investigate the biological activity of cell-derived soluble LIGHT, endothelial cells were incubated with LIGHT-containing supernatants derived from activated 

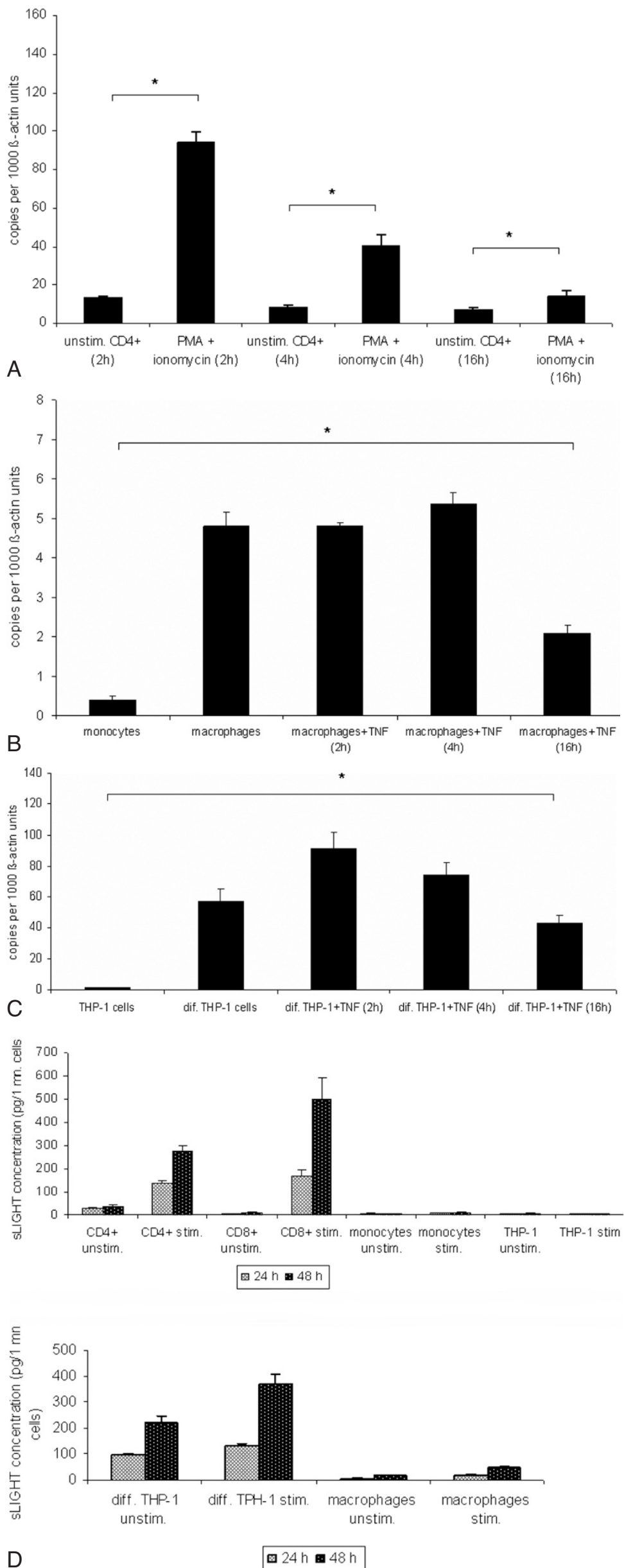

Fig. $2 A-2 C$. mRNA expression of LIGHT in immune cells. T cells were stimulated with PMA and ionomycin for 2, 4 or 16 hours. PMA differentiated THP-1 cells, monocyte-derived macrophages were further stimulated with TNF- $\alpha$ for 2,4 or 16 hours. Expression of LIGHT was assessed at different time points by RT-PCR. Maximum of LIGHT expression in T cells was observed after 2 hours after stimulation (Fig. 2A). *P $<0.05$ vs unstimulated cells. In differentiated THP-1 cells and monocyte-derived macrophages maximum LIGHT expression peaked after 4 hours at the mRNA-level (Fig. 2B and 2C). *P $<0.05$ vs monocytes and THP-1 cells. These data correspond to one representative experiment from three performed. 


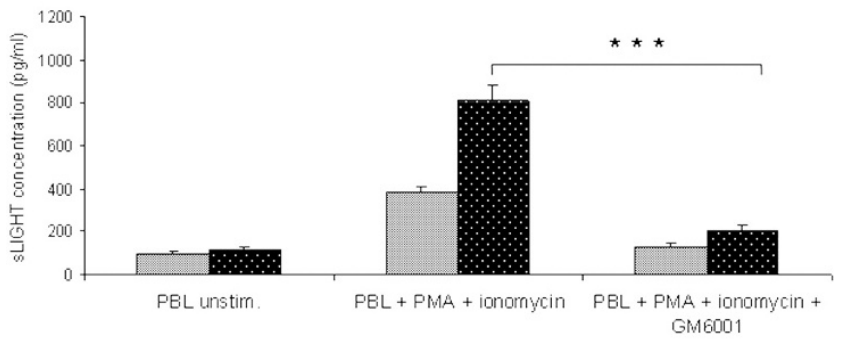

A

a $24 \mathrm{~h} \cdot 48 \mathrm{~h}$

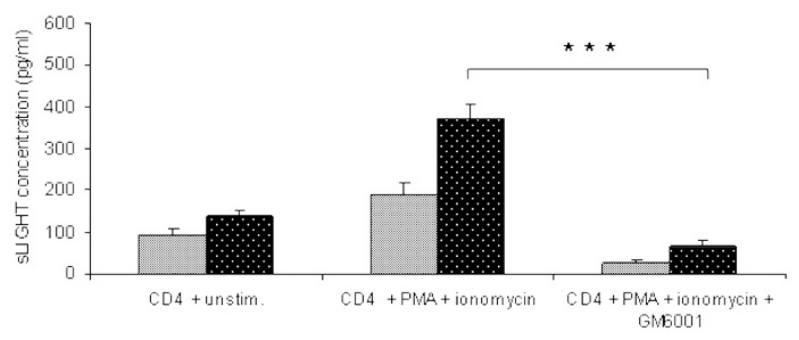

B $\square 24 \mathrm{~h}-48 \mathrm{~h}$

Fig. $3 A$ - 3B. Matrix metalloproteinase (GM6001) mediates shedding of soluble LIGHT. 30 minutes prior to activation of $\mathrm{PBL}$ and $\mathrm{CD}^{+}{ }^{+}$subsets with PMA metalloproteinase inhibitor GM6001 $(30 \mu \mathrm{M})$ was added to the medium. After 24 hours and 48 hours the conditioned medium was analyzed for the presence of soluble LIGHT by ELISA. MMP inhibitor markedly reduced the release of soluble LIGHT in lymphocytes (Fig. 3A and 3B). Values represent the mean \pm SD of soluble LIGHT analyzed in triplicate. $* * * \mathrm{P}<0.0005$ vs without GM6001 treated cells.

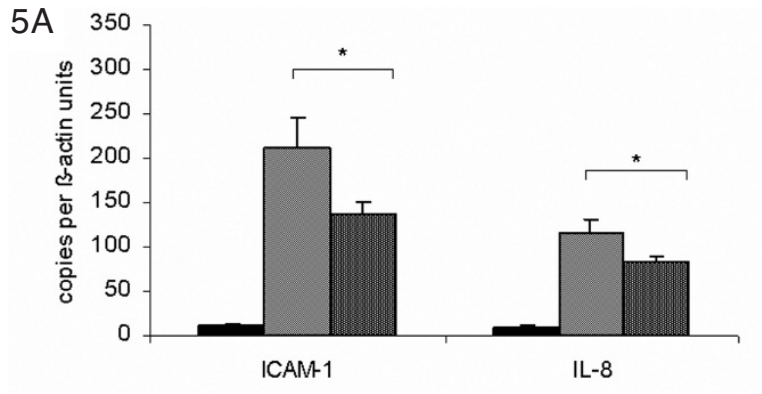

a HUVEC $\square$ HUVEC+ PBL supernatant $\mathbf{m}$ HUVEC+ PBL supernatant+ Ab

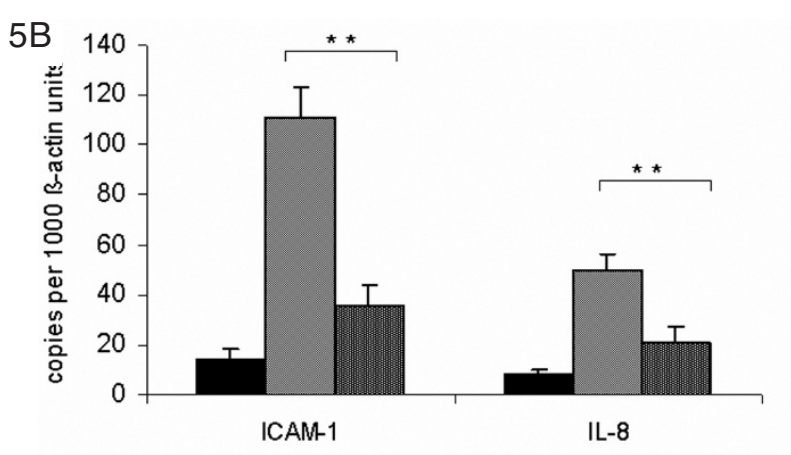

-HUVEC aHUVEC+isol. sLIGHT I HUVEC+isol. sLIGHT+ Ab

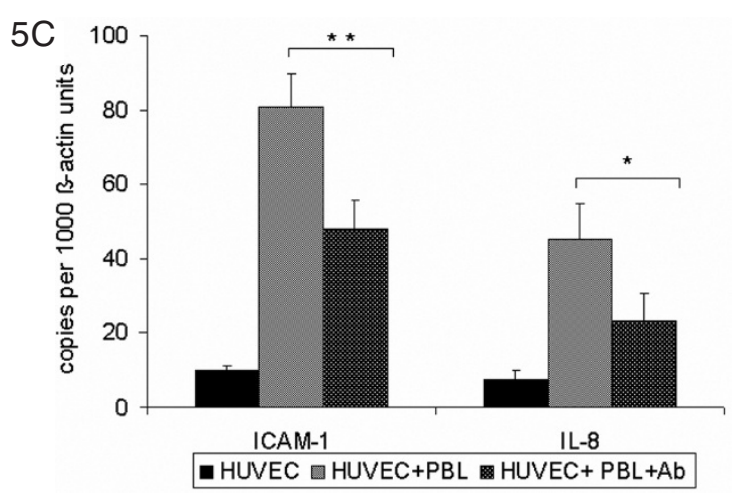

lymphocytes (PMA $100 \mathrm{ng} / \mathrm{ml}+$ ionomycin $1 \mu \mathrm{g} / \mathrm{ml}$ ). After stimulation of HUVECs for 3 hours a marked up-regulation of ICAM-1 and IL-8 was shown by RTPCR (Fig. 5A). Similar results were obtained with soluble LIGHT isolated by size exclusion chromatography (Fig. 5B). Pre-incubation of LIGHT-containing supernatants with anti-LIGHT $\mathrm{mAb}$ resulted in a partial re-

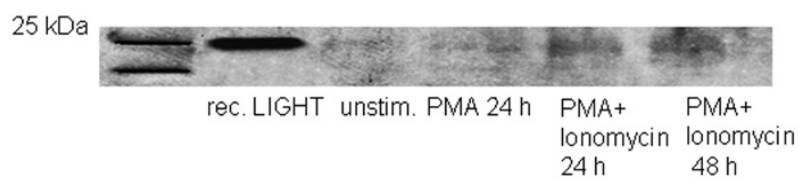

Fig. 4. Monomeric size of soluble LIGHT. To determine the monomoric size of soluble LIGHT, supernatants of PMA (100 $\mathrm{ng} / \mathrm{ml}+$ ionomycin $1 \mu \mathrm{g} / \mathrm{ml}$ ) activated PBMCs were collected after 48 hours and concentrated with Microcon centrifugal filters YM50. Soluble LIGHT production in supernatant was then assessed by ELISA. Molecular mass of monomeric LIGHT was detected by Western blotting. 50 ng of recombinant sLIGHT were loaded in one lane as a control (Fig. 4).

Fig. $5 A-5 C$. Induction of ICAM-1 and IL-8 by lymphocyte-derived membrane-bound and soluble LIGHT in human endothelial cells. Human endothelial cells were co-incubated in supernatant containing soluble LIGHT, isolated soluble LIGHT and stimulated (PMA 100ng/ml + ionomycin 1 $\mu \mathrm{g} / \mathrm{ml}$ ) and unstimulated whole lymphocytes for 3 hours. Thereafter, HUVECS were harvested and analyzed for expression of the adhesion molecule ICAM- 1 and IL- 8 by real-time PCR. After stimulation ICAM-1 and IL- 8 were significantly increased in all experiments (Fig. 5A-5C). To confirm that the stimulation of the endothelial cells was due to LIGHT, specific anti-LIGHT-antibodies were used. After pre-incubation of whole lymphocytes and LIGHT containing medium with antiLIGHT antibody, cytokine induction was partially abolished. After pre-treatment of isolated LIGHT containing medium with anti LIGHT, the effects were even completely abolished (Fig. 5B). These data correspond to one representative experiment of three performed. $* \mathrm{P}<0.05$ and $* * \mathrm{P}<0.005$ vs stimulated cells without blocking antibody.

duction of these cytokines; with isolated soluble LIGHT antibody preincubation resulted in almost complete inhibition of up-regulation of ICAM-1 and IL-8. Membrane-bound LIGHT of stimulated PBMC was shown to induce up-regulation of ICAM-1 and IL8 when co-incubating whole-cell PBMC with endothelial cells (Fig. 5C). Pre-incubation of PBMC with anti- 


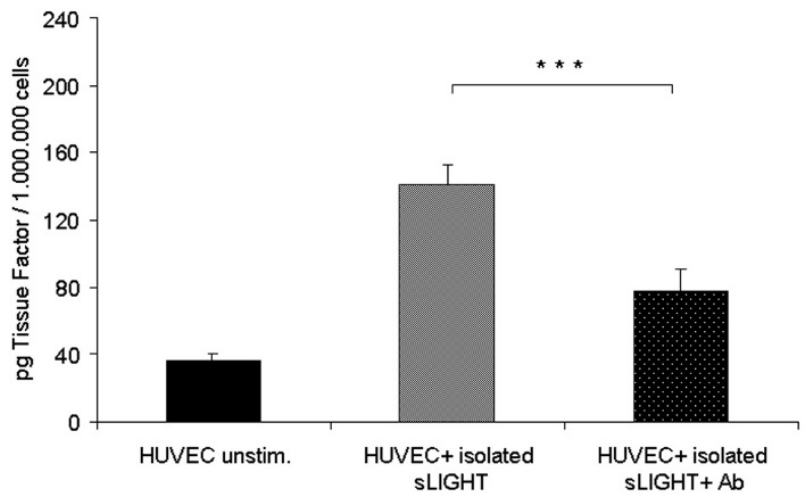

Fig. 5D. Induction of tissue factor (TF) activity by recombinant LIGHT in human endothelial cells. Endothelial cells were stimulated with isolated soluble LIGHT, harvested after 6 hours and assayed for procoagulant activity as described under "Materials and Methods". LIGHT induced a marked up-regulation of tissue factor in endothelial cells. TF activity of each sample was determined based on comparison with a standard curve established with known amounts of recombinant TF. The data represent the mean of three independent experiments performed (Fig. 5D). ${ }^{* * *} \mathrm{P}<0.0005$ vs stimulated cells without bocking antibody.

d)

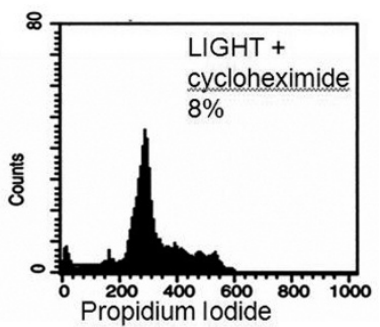

e)

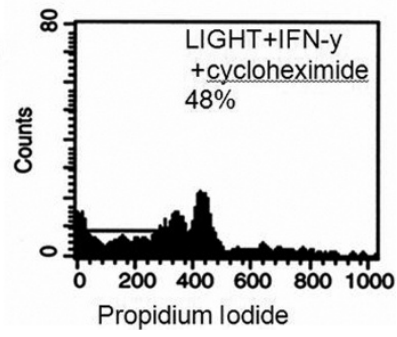

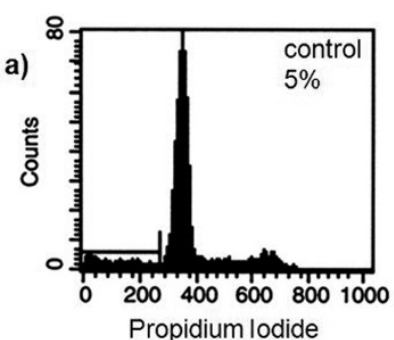

b)
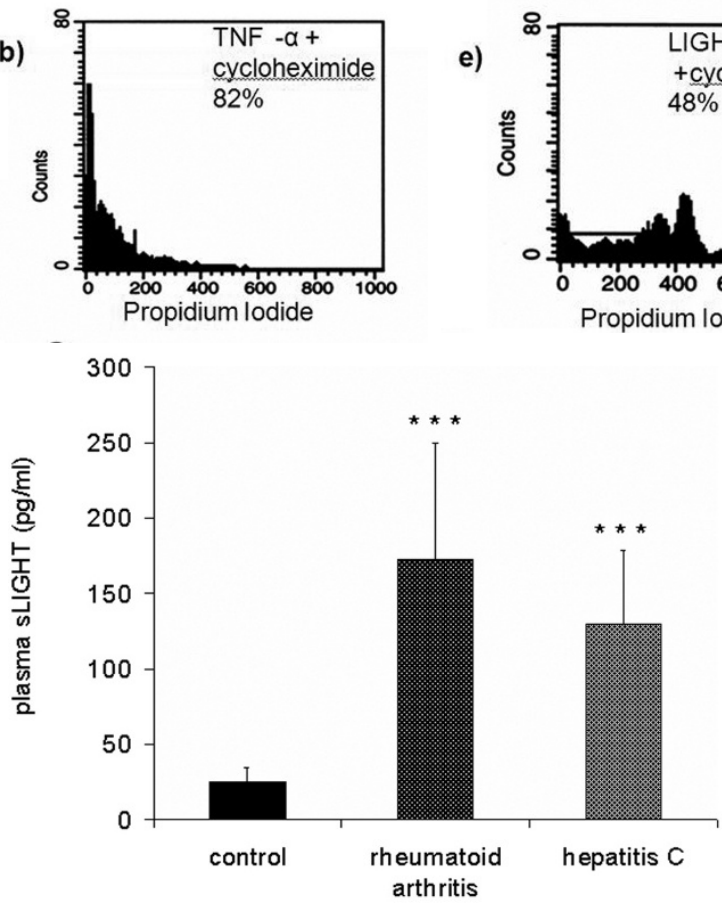

LIGHT resulted in partial inhibition of ICAM-1 and IL-8 up-regulation, suggesting a substantial contribution of cell-bound LIGHT to this up-regulation. Similar results were obtained when using PMA-stimulated $\mathrm{CD}^{+}-\mathrm{T}$ cells (data not shown). Furthermore, induction of tissue factor activity by isolated soluble LIGHT in endothelial cells could be shown by one stage-clotting assay (Fig. 5D), which again was inhibitable by antibody pre-incubation.

\section{LIGHT-MEdiATEd Apoptosis In HUVEC}

There have been many studies addressing the role of LIGHT in apoptosis, especially with tumour cell lines expressing both receptors TR2 and LTßR. LIGHT alone did not induce apoptosis in endothelial cells.
Fig. 6. Induction of apoptosis in endothelial cells by recombinant LIGHT. LIGHT induced apoptosis endothelial cells after preincubation with IFN- $\gamma$. Endothelial cells were incubated with medium, soluble LIGHT, TNF- $\alpha$, cycloheximide alone or in combination with TNF- $\alpha$ or LIGHT for 24 hours. Thereafter harvested and analyzed for propidium iodide exclusion by FACS analysis. IFN- $\gamma$ plus cycloheximide alone did not induce apoptosis (control). LIGHT combined with cycloheximide induced apoptosis in endothelial cells after pre-treatment with IFN- $\gamma$ (Fig. 6). IFN- $\gamma$ alone had no effect on endothelial cells (not shown). The data represent the mean \pm SD of three independent experiments performed.
Fig. 7. Enhanced plasma levels of soluble LIGHT in patients with hepatitis $\mathrm{C}$ and rheumatoid arthritis. Plasma levels of LIGHT was measured by ELISA in patients with hepatitis C $(n=10)$, rheumatoid arthritis $(n=22)$ and 16 healthy controls. Soluble LIGHT concentration was normalized to cell numbers ( $\mathrm{pg} / 1$ million cells). The data represent the mean $\pm \mathrm{SD}$ of three independent experiments performed (Fig. 7). ***P < 0.0005 vs healthy controls.

Since previous studies reported that LIGHT, in combination with IFN- $\gamma$ induced cell death through LTßR in several cancer cell lines, endothelial cells were preincubated with IFN- $\gamma(25 \mathrm{U} / \mathrm{ml})$ for 24 hours prior to apoptosis induction. Such IFN- $\gamma$ pretreated endothelial cells were fully susceptible to LIGHT-mediated apoptosis (Fig. 6). IFN- $\gamma$ alone had no effect on endothelial cells (not shown).

\section{InCReased Plasma Levels of LiGHT in Hepatitis C and Rheumatoid Arthritis Patients}

Involvement of LIGHT in human atherosclerosis, synovialitis of rheumatoid arthritis or pathogenesis of experimental rodent liver inflammation has been reported. To elucidate the potential systemic relevance 
of soluble LIGHT in inflammatory diseases like hepatitis C or rheumatoid arthritis, plasma levels of LIGHT of these patients was examined by ELISA (Fig. 7). While healthy controls showed low, but distinct serum concentrations of soluble LIGHT ( $\mathrm{n}=$ 16), patients with hepatitis $C(n=10)$ and rheumatoid arthritis $(n=22)$ showed several-fold increased plasma levels of soluble LIGHT. (Hepatitis C: $129.53 \pm 49.14$ $\mathrm{pg} / \mathrm{ml}$, rheumatoid arthritis: $172.13 \pm 77.64 \mathrm{pg} / \mathrm{ml}$; both $\mathrm{p}<0.0005)$.

\section{Discussion}

The tumor necrosis factor superfamily member LIGHT plays an important role in regulating the immune response and LIGHT may play a prominent role in predominantly $\mathrm{T}$ cell mediated pathologies. Several studies have demonstrated the expression of LIGHT in different cell types and its potential role in inflammatory diseases $[15,16]$. Recently, we have shown that platelet-associated LIGHT is involved in the adhesion of platelets to endothelial cells under static and highshear dynamic flow conditions [11]. Furthermore our result showed enhanced plasma levels of LIGHT in patients with acute myocardial infarction. These findings were in agreement with the results of Otterdal et al.10 and strengthen the notion of the potential role of platelet-derived LIGHT in coronary heart disease. Although the expression of LIGHT has been shown in different cell types, including platelets, the relative contribution of various cellular origins to soluble LIGHT as well as the relevance and biological activity of soluble LIGHT secreted by different cells has not been investigated. In this study we compared the quantitative expression of LIGHT in different immune cells and the biological activity of soluble LIGHT upon endothelial cells as an exemplary readout system.

Here, we could show that among the immune cells, $\mathrm{CD}^{+} / \mathrm{CD}^{+} \mathrm{T}$ cells are the main source of soluble LIGHT. Circulating monocytes do not express LIGHT, but differentiation into macrophages resulted in expression of LIGHT, even more so in differentiated THP-1 cells. Secretion of soluble LIGHT was matrix metalloproteinase-dependent and led to inflammatory changes in endothelial cells measured as up-regulation of adhesion molecules (ICAM-1), pro-coagulant factors (TF) and release of chemokines (IL-8). Size determination of soluble LIGHT revealed a molecular mass of approximately $60 \mathrm{kDa}$, suggesting a trimeric form similar to other TNFSF members. Furthermore, patients with chronic inflammatory diseases such as hepatitis $\mathrm{C}$ and rheumatoid arthritis showed enhanced concentrations of soluble LIGHT compared to healthy controls.

Basal cellular expression of LIGHT on mRNA and surface protein levels was significantly increased in peripheral blood mononuclear cells or isolated $\mathrm{CD}^{+}$/ $\mathrm{CD}^{+} \mathrm{T}$ cells after stimulation. Stimulated monocytes or monocyte-like THP-1 cells lacked expression of LIGHT, but differentiation of THP-1 cells into macrophages resulted in a marked upregulation of LIGHT. Monocyte-derived macrophages showed only a weak expression of LIGHT.
Soluble LIGHT could be detected in large amounts in the supernatants of $\mathrm{CD}^{+} / \mathrm{CD}^{+} \mathrm{T}$ cells as well as differentiated THP-1 cells, but not in the supernatants of THP-1 cells and monocytes. Ultrafiltration experiments excluded membrane fragments of ruptured / dead cells as the source of soluble LIGHT. In recently published data involvement of platelet-derived LIGHT in acute coronary syndromes was suggested $[10,11]$, but based on recently published data by Ivandic et al. [12] that release of platelet-mediated cytokines are mostly influenced by preanalytical conditions through ex vivo activation, the actual relevance and contribution of platelet- derived LIGHT in atherosclerosis might have been misinterpreted or overestimated. Clinical relevance of other platelet-derived inflammatory cytokines was shown for soluble CD40 ligand [17]; increased concentrations of sCD40L were reported mostly in disorders associated with platelet activation such as acute and stable coronary artery disease $[18,19]$. However, Ivandic et al.12 recently reported that increased sCD40 L concentrations by platelets were dependent on sample preparation; no disease-related in vivo activation of platelets was observed.

LIGHT has been claimed that it exists in several distinct molecular forms, which are directed to distinct cellular compartments, including the extracullar space, the membrane, and the cytosol [20], however, PCR data in our experiments consistently showed a single band for LIGHT (not shown). Furthermore, our data indicate that similar to soluble CD40 ligand [21] shedding of soluble LIGHT is mediated by metalloproteinase from the cell surface. Metalloproteinase inhibitor reduced significantly the release of soluble LIGHT and no separate mRNA or cDNA form of soluble LIGHT was detectable.

Size determination of immune cell-derived soluble LIGHT by gel exclusion chromatography and filter cartridge centrifugation revealed a molecular mass of approximately $60 \mathrm{kDa}$ and provide first evidence for a trimeric form since western blot analysis shows a monomeric size of $23-25 \mathrm{kDa}$. It can be speculated that similar to other TNFSF members, LIGHT is assembled to and functions as a homotrimer. These results implicate that release of LIGHT, at least partly, is due to the action of metal-dependent enzymes.

Endothelial cells play a critical role in the control of vascular function and participate in inflammatory and immune reactions. Herein we showed that immune cell-derived membrane-bound and soluble LIGHT is a potent inducer of ICAM-1, tissue factor and IL-8. After incubation of endothelial cells with LIGHT containing supernatant or isolated soluble LIGHT inflammatory cytokines were up-regulated. The effects of LIGHT-containing supernatants could however, only partially be blocked by anti-LIGHT antibody. When using LIGHT isolated und purified by gel exclusion chromatography from cell supernatants, LIGHT-mediated activation of endothelial cells could be almost completely blocked by specific antibody, strongly supporting the notion of specific biologic activity of immune cell-mediated soluble LIGHT. While several studies have examined the cytotoxic effects of LIGHT on tumor cell lines in culture and its ability to prevent 
tumor formation in mice $[3,22]$, induction of apoptosis in endothelial cell has not been addressed yet. Our findings indicate that soluble LIGHT is also able to induce apoptosis in IFN- $\boldsymbol{\gamma}$-pretreated endothelial cells. IFN- $\gamma$ has been reported to be involved in inflammatory responses, e. g. its expression in atherosclerotic plaques [23]. Since, we found that LIGHT-mediated apoptosis occurs only in IFN- $\gamma$-pretreated endothelial cells, it is likely that both, LIGHT and IFN- $\gamma$, work in concert to enhance inflammatory reactions.

Recently Dahl et al. [24] could show myocardial expression of LIGHT in ischemic and non-ischemic regions of the left ventricle in patients with end-stage heart failure undergoing cardiac transplantation. In this patient collective HVEM (herpesvirus entry mediator) was up-regulated in circulating monocytes, accompanied by increased expression of LIGHT in circulating T cells. Furthermore, LIGHT-mediated IL-6 expression in PBMC and endothelial cells could be shown in patients with chronic heart failure, underscoring a role for LIGHT in the progression of heart failure. In our study we show increased plasma levels of soluble LIGHT in patients with chronic hepatitis C and rheumatoid arthritis as an example for inflammatory diseases where activated T cells play a key role. As our data show that monocytes do not express LIGHT and resident macrophages show only a slight expression while circulating $\mathrm{T}$ cells have the highest LIGHT expression, it might be speculated that activated $\mathrm{T}$ cells are the main source of circulating LIGHT in inflammatory or infectious conditions. In terms of platelet-derived LIGHT, the quantitative contribution by platelets is difficult to asses because of ex vivo activation.

These findings implicate that soluble LIGHT originates not only from platelets, but largely from immune cell activation during systemic inflammation or infection.

In summary, rather than representing "disposal mechanism" shedding/release of soluble LIGHT represents a relevant biological activation process leading to pro-inflammatory changes e. g. in endothelial cells, where the interaction with $\mathrm{T}$ cell activation and platelet function/adhesion may accelerate atherothrombotic pathways. Soluble LIGHT however, does not appear to be exclusively produced by platelets and macrophages as suggested previously, but elevated LIGHT serum concentrations seen in diverse inflammatory or infectious pathologies, most likely are derived from activated immune cells. The diagnostic/ prognostic efficacy of soluble LIGHT determination in various clinical states will have to be determined in more detail in future studies. Nonetheless, diagnostic determinations or therapeutic inhibition of the LIGHT pathway may become useful research developments in various clinical pathologies.

\section{REFERENCES}

1. Aggarwal BB. Signalling pathways of the TNF superfamily: a double-edged sword.Nat Rev Immunol. 2003 Sep; 3(9):745-56

2. Tamada K, Shimozaki K, Chapoval AI, Zhai Y, Su J, Chen SF, Hsieh SL, Nagata S, Ni J, Chen L. LIGHT, a TNF-like molecule, costimulates $T$ cell proliferation and is required for dendritic cell-mediated allogeneic T cell response J Immunol. 2000 Apr 15;164(8):4105-10

3. Scholz H, Sandberg W, Damas JK, Smith C, Andreassen AK, Gullestad L, Froland SS, Yndestad A, Aukrust P, Halvorsen B. Enhanced plasma levels of LIGHT in unstable angina: possible pathogenic role in foam cell formation and thrombosis. Circulation. 2005;112:2121-2129.

4. Schneider K, Potter KG, Ware CF. Lymphotoxin and LIGHT signaling pathways and target genes.Immunol Rev. 2004 Dec;202:49-66. Review

5. Anand S, Wang P, Yoshimura K, Choi IH, Hilliard A, Chen YH, Wang CR, Schulick R, Flies AS, Flies DB, Zhu G, Xu Y, Pardoll DM, Chen L, Tamada K. Essential role of TNF family molecule LIGHT as a cytokine in the pathogenesis of hepatitis. J Clin Invest. 2006 Apr;116(4): 1045-51. Epub 2006 Mar 23

6. Lee WH, Kim SH, Lee Y, Lee BB, Kwon B, Song H, Kwon BS, Park JE. Tumor necrosis factor receptor superfamily 14 is involved in atherogenesis by inducing proinflammatory cytokines and matrix metalloproteinases. Arterioscler Thromb Vasc Biol. 2001 Dec;21(12): 2004-10

7. Otterdal K, Smith C, Oie E, Pedersen TM, Yndestad A, Stang E, Endresen K, Solum NO, Aukrust P, Damas JK. Platelet-derived LIGHT induces inflammatory responses in endothelial cells and monocytes. Blood. 2006.

8. Celik S, Langer H, Stellos K, May AE, Shankar V, Kurz K, Katus HA, Gawaz MP, Dengler TJ. Platelet-associated LIGHT (TNFSF14) mediates adhesion of platelets to human vascular endothelium. Thromb Haemost. 2007 Oct; 98(4):798-805

9. Ivandic BT, Spanuth E, Haase D, Lestin HG, Katus HA. Increased plasma concentrations of soluble CD40 ligand in acute coronary syndrome depend on in vitro platelet activationClin Chem. 2007 Jul;53(7):1231-4. Epub 2007 May 10

10. Pober JS, Bevilacqua MP, Mendrick DL, Lapierre LA, Fiers W, Gimbrone MA, Jr. Two distinct monokines, interleukin 1 and tumor necrosis factor, each independently induce biosynthesis and transient expression of the same antigen on the surface of cultured human vascular endothelial cells. J Immunol. 1986; 136:1680-1687.

11. Kluger MS, Johnson DR, Pober JS. Mechanism of sustained E-selectin expression in cultured human dermal microvascular endothelial cells. J Immunol. 1997;158:887896.

12. Nawroth PP, Stern DM, Kisiel W, Bach R.Cellular requirements for tissue factor generation by bovine aortic endothelial cells in cultureThromb Res. 1985 Dec 1;40(5): 677-91

13. Arnett FC, Edworth SM, Bloch DA, McShane DJ, Fries JF, Cooper NS, Healey LA, Kaplan SR, Liang MH, Luthra HS (1988) The American Rheumatism Association 1987 revised criteria for the classification of rheumatoid arthritis. Arthritis Rheumatism 31:315-324

14. Mauri DN, Ebner R, Montgomery RI, Kochel KD, Cheung TC, Yu GL, Ruben S, Murphy M, Eisenberg RJ, Cohen GH, Spear PG, Ware CF. LIGHT, a new member of the TNF superfamily, and lymphotoxin alpha are ligands for herpesvirus entry mediator. Immunity. 1998;8:21-30.

15. Anand S, Wang P, Yoshimura K, Choi IH, Hilliard A, Chen YH, Wang CR, Schulick R, Flies AS, Flies DB, Zhu G, Xu Y, Pardoll DM, Chen L, Tamada K. Essential role of TNF family molecule LIGHT as a cytokine in the pathogenesis of hepatitis. J Clin Invest. 2006 Apr;116(4): 1045-51. Epub 2006 Mar 23

16. Kim WJ, Kang YJ, Koh EM, Ahn KS, Cha HS, Lee WH.LIGHT is involved in the pathogenesis of rheumatoid arthritis by inducing the expression of pro-inflammatory cytokines and MMP-9 in macrophages. Immunology. 2005 Feb;114(2):272-9 
17. Aukrust P, Muller F, Ueland T, Berget T, Aaser E, Brunsvig A, Solum NO, Forfang K, Froland SS, Gullestad L. Enhanced levels of soluble and membranebound CD40 ligand in patients with unstable angina. Possible reflection of $\mathrm{T}$ lymphocyte and platelet involvement in the pathogenesis of acute coronary syndromes. Circulation. 1999;100:614-620)

18. Garlichs CD, John S, Schmeisser A, Eskafi S, Stumpf C, Karl M, Goppelt-Struebe M, Schmieder R, Daniel WG. Upregulation of CD40 and CD40 ligand (CD154) in patients with moderate hypercholesterolemia. Circulation. 2001 Nov 13;104(20):2395-400

19. Marx N, Imhof A, Froehlich J, Siam L, Ittner J, Wierse G, Schmidt A, Maerz W, Hombach V, Koenig W. Effect of rosiglitazone treatment on soluble CD40L in patients with type 2 diabetes and coronary artery disease. Circulation. 2003 Apr 22;107(15):1954-7. Epub 2003 Apr 14.

20. Granger SW, Butrovich KD, Houshmand P, Edwards WR, Ware CF.Genomic characterization of LIGHT reveals linkage to an immune response locus on chromosome $19 \mathrm{p} 13.3$ and distinct isoforms generated by alternate splicing or proteolysis J Immunol. $2001 \mathrm{Nov}$ $1 ; 167(9): 5122-8$

21. Contin C, Pitard V, Itai T, Nagata S, Moreau JF, Déchanet-Merville J. Membrane-anchored CD40 is processed by the tumor necrosis factor-alpha-converting enzyme. Implications for CD40 signaling. J Biol Chem. 2003 Aug 29;278(35):32801-9. Epub 2003 Jun 16

22. Zhai Y, Guo R, Hsu TL, Yu GL, Ni J, Kwon BS, Jiang GW, Lu J, Tan J, Ugustus M, Carter K, Rojas L, Zhu F,
Lincoln C, Endress G, Xing L, Wang S, Oh KO, Gentz R, Ruben S, Lippman ME, Hsieh SL, Yang D. LIGHT, a novel ligand for lymphotoxin beta receptor and TR2/HVEM induces apoptosis and suppresses in vivo tumor formation via gene transfer. J Clin Invest. 1998 Sep 15;102(6):1142-51

23. Tellides G, Tereb DA, Kirkiles-Smith NC, Kim RW, Wilson JH, Schechner JS, Lorber MI, Pober JS.Interferongamma elicits arteriosclerosis in the absence of leukocytes.Nature. 2000 Jan 13;403(6766):207-11.

24. Dahl CP, Gullestad L, Fevang B, Holm AM, Landrø L, Vinge LE, Fiane AE, Sandberg WJ, Otterdal K, Frøland SS, Damås JK, Halvorsen B, Aukrust P, Oie E, Yndestad A. Increased expression of LIGHT/TNFSF14 and its receptors in experimental and clinical heart failure. Eur J Heart Fail. 2008 Apr;10(4):352-9. Epub 2008 Mar 18

Received: March 8, 2009 / Accepted: March 12, 2009

Address for correspondence:

Thomas Dengler, M.D.

Department of Cardiology

University of Heidelberg

Im Neuenheimer Feld 410

69120 Heidelberg

Germany

Phone: +49-(0)6221-56-38681

Fax: +49-(0)6221-56-5515,

E-mail: thomas.dengler@med.uni-heidelberg.de 